\title{
FÁBIO ERBER: O ECONOMISTA E SUAS CIRCUNSTÂNCIAS
}

\author{
Luiz Carlos Delorme Prado ${ }^{(*)}\left(^{* *}\right.$
}

\section{INTRODUÇÃO}

A vida profissional de Erber deu-se nos quarenta anos compreendidos entre o período que ficou conhecido como "milagre econômico" e o fim do segundo governo Lula. Como economista do desenvolvimento, presenciou a euforia do crescimento acelerado e o fracasso do projeto desenvolvimentista. Foi observador, analista e crítico das reformas econômicas conservadoras que foram capazes de encerrar um longo ciclo de alta inflação, mas criaram as bases de uma nova convenção que, na visão de Erber, era pouco funcional à retomada de um projeto de desenvolvimento de longo prazo. Atuou como pesquisador, professor e policy maker em Política Científica e Tecnológica e em Política Industrial. Participou de governos, como secretário adjunto do Ministério de Ciência e Tecnologia e (duas vezes) como diretor do BNDES.

Não é possível resenhar a contribuição teórica de um economista, sem analisar seu tempo. Hobsbawm, com seu olhar refinado de historiador, lembrou aos economistas, quando proferiu, em 1980, as Marshall Lectures, na Universidade de Cambridge ${ }^{1}$, que:

economia é uma ciência aplicada, assim como medicina é uma ciência natural aplicada. Biólogos que não têm por objetivo curar doenças, como sua tarefa principal, não são médicos, mesmo que estejam associados à escola de medicina. Economistas que não estão primeiramente preocupados, direta ou indiretamente, com a operação de economias reais, que querem transformar, melhorar ou proteger contra deterioração, podem ser melhor classificados como uma subespécie de filósofos ou matemáticos, a menos que desejem ocupar o espaço vago pela teologia em nossas sociedades seculares.

\footnotetext{
* Professor do Instituto de Economia da UFRJ, Ph.d em Economia, Queen Mary College, Universidade de Londres. Contato: 1cdprado@gmail.com .

** Agradeço as conversas e sugestões de Paulo Tigre, que chamou minha atenção sobre a atmosfera intelectual da Universidade de Sussex, ao final da década de 1970. Agradeço, também, a Victor Prochnick e a Fábio Sá Earp, por conversas e comentários sobre este ensaio. Agradeço, sobretudo, à Ana Erber, que me deu acesso à biblioteca de Fabio Erber e me emprestou exemplares de muitos de seus trabalhos aos quais não tinha acesso. Agradeço à Ana, sobretudo pela paciência e gentileza que sempre me recebeu em sua casa, durante as muitas horas que ficava conversando com Fábio Erber sobre assuntos nem sempre relevantes, mas sempre instigantes. Dedico a ela esse ensaio.
}

${ }^{1}$ HOBSBAWM (1997, p. 96-97). 
Erber era um economista, no sentido indicado por Hobsbawm. Entendia essa disciplina como uma ciência social aplicada, que devia não apenas discutir o mundo real, mas transformá-lo. Ao longo de sua vida profissional, Erber exerceu muitas funções e produziu um grande número de artigos e capítulos de livro. Recebeu muitas influências, desde autores de tradição cepalina, como Celso Furtado e Fajnzylber², da literatura de economia do desenvolvimento, como Hischman, a quem muito apreciava, de autores vinculados à discussões de História e desenvolvimento, como Gerschenkron, de autores da literatura de comércio internacional e crescimento, como Posner, Linder e Johnson ${ }^{3}$, dos neoschumpeterianos, como Freeman e de seus muitos amigos, com quem mantinha constantes conversas sobre questões de economia do desenvolvimento, no Brasil, na Argentina, na França e em outros lugares do mundo.

No entanto, identifico um elemento unificador em sua obra: uma concepção de desenvolvimento que se manteve constante durante quase toda sua vida. Para esse autor, desenvolvimento era uma política, um processo, e economista do desenvolvimento é um profissional que estuda, teoriza e implementa políticas de desenvolvimento. Por sua vez, o conceito de desenvolvimento do autor tem duas fontes, sob muitos aspectos convergentes: as definições de Kuznetz e Schumpeter ${ }^{4}$.

Para Kuznetz, o crescimento moderno tinha características quantitativas, associadas à taxa de crescimento agregado, características relacionadas à transformação estrutural e relacionadas à difusão dos seus efeitos pela economia mundial. No entanto, para Kuznetz, essas mudanças tinham uma fonte primordial do crescimento, que era a onda de inovações que geravam as transformações da economia. Mas a fonte dessas transformações era "a ascensão da ciência moderna como a base do avanço da tecnologia"s.

Erber tratou, em toda sua obra, de desenvolvimento econômico como um processo que envolvia taxas de crescimento per capita elevadas, aumento de produtividade, mas, sobretudo, mudanças estruturais na economia e na sociedade, que implicavam

\footnotetext{
${ }^{2}$ Erber apreciava, sobretudo, Furtado (1959) e Fajnzylber (1990).

${ }^{3}$ Ver, em especial, Posner (1961), Linder (1961), Johnson (1968).

${ }^{4}$ Essas fontes nunca ficaram explícitas em suas obras. No entanto, através da análise de seus artigos, essas influências ficam evidentes. Embora deixe claro que esta afirmação é uma interpretação do autor desta resenha, ela é consistente com longas conversas que o autor teve com o resenhado.

${ }^{5}$ Kuznetz (1973, p. 249). Kuznetz verificou seis características do crescimento econômico moderno: (1) Elevadas taxas de crescimento do produto per capita e da população; (2) Aumento da taxa de produtividade; (3) Elevada taxa de transformações estruturais da economia; (4) Rápida mudança na estrutura da sociedade e de sua ideologia; (5) Os países desenvolvidos, devido à sua tecnologia mais avançada, afetam a economia do mundo todo, tornando-o em grande medida interligado; (6) O crescimento econômico moderno difundiu-se imperfeitamente, limitando-se a produzir a totalidade de seus efeitos em uma pequena parte de países industriais avançados. Essa classificação de Kuznetz foi apresentada em sua palestra em Estocolmo, Suécia, quando recebeu o Prêmio Nobel em economia. O trabalho foi publicado posteriormente na American Economic Review. Ver Kuznetz, 1973.
} 
alterações no comportamento dos agentes econômicos. A ideia de que o processo de desenvolvimento tinha como condição necessária mudanças nas instituições e na cultura esteve sempre presente na obra desse autor. Em seus trabalhos finais, chamou de convenção de desenvolvimento esse comportamento coletivo que produzia (ou que era compatível com) a mobilização da sociedade voltada para o desenvolvimento. Erber, como muitos de sua geração, priorizava uma estratégia de desenvolvimento baseada no crescimento industrial, que, combinado com incorporação de ciência e tecnologia, seria a matriz da mudança estrutural. Sua agenda era a moderna, via o mundo por um olhar social democrata, de forma compatível com as famosas Conferências de Cambridge de T.H. Marshall ${ }^{6}$. Nunca foi entusiasta de uma agenda pós-moderna: questões como o meio-ambiente e outros temas relacionados com a agenda pós-moderna no debate sobre desenvolvimento não lhe interessavam.

De Schumpeter, Erber buscou três elementos que, também, mantiveram-se em toda sua obra. Em primeiro lugar, a ideia de que desenvolvimento era um processo endógeno à vida social e exógeno a variáveis exclusivamente econômicas - ou seja, desenvolvimento não é obtido ou explicado por variáveis apenas econômicas. Desenvolvimento não pode ser alcançado através de alterações exógenas simples, como, por exemplo, alterações de políticas macroeconômicas ${ }^{7}$. Embora, sensível à necessidade de políticas macroeconômicas consistentes, e nesse aspecto simpático à abordagem pós-keynesiana, para Erber, a essência da política de desenvolvimento era a capacidade de alterar o comportamento dos agentes econômicos, através de mecanismos que passavam por alteração de mentalidades, políticas de inovação, políticas industriais, políticas de promoção de concorrência etc.

A segunda idéia schumpeteriana é a distinção entre crescimento, visto como mudança incremental, e desenvolvimento, visto como uma descontinuidade no estado estacionário, ou seja, uma quebra na regularidade contemporânea levando a um novo futuro indeterminado. Essa discontinuidade foi definida por Schumpeter da seguinte forma:

transição de uma norma do sistema econômico em outra norma de tal forma que essa transição não pode ser decomposta em passos infinitesimais ${ }^{8}$.

A terceira idéia schumpeteriana é a dinâmica da introdução do progresso técnico, como promovendo um ganho de monopólio, que será desafiado pela resposta de

\footnotetext{
${ }^{6}$ Ver T. H. Marshall (1967). Muitas vezes Erber comentava que ficaria satisfeito se o governo do PT fosse capaz de implementar uma política social democrata consistente.

${ }^{7}$ Schumpeter (1988, p. 47).

${ }^{8}$ Schumpeter (2005, p. 115). O texto citado é de um artigo de Schumpeter, escrito originariamente em 1932, e que foi encontrado pelo scholar alemão, Hans Eblinger e publicado com introdução escrita por Becker, Eblinger et al., no JEL, em 2005.
} 
seus concorrentes, forçados, também, a responder através de inovação. Essa terceira idéia schumpeteriana, no entanto, ficará mais presente na obra do Fábio ao final de sua vida, quando inclusive chegou a fazer vários pareceres em questões de direito da concorrência, enfatizando aspectos dinâmicos da relação entre antitruste e inovação no processo produtivo 9 .

Este ensaio discutirá a obra de Fábio Erber, cronologicamente, escolhendo artigos e temas que marcaram sua trajetória. Qualquer leitura de uma longa obra é influenciada pelo momento em que é feita. Não há, na escolha dos artigos, uma preocupação de selecionar os mais importantes. A escolha foi feita pelas preocupações que, a meu juízo, foram relevantes em cada época. Trata-se de estudar o intelectual e suas circunstâncias. O olhar é de um historiador econômico e não de um historiador das ideias econômicas.

\section{ORIGENS DO DEBATE SOBRE CIÊNCIA E TECNOLOGIA E DESENVOLVIMENTO}

Erber fez parte da primeira geração de intelectuais brasileiros que estudaram no exterior com apoio público. Até a década de 1960, os graus de mestrado e doutorado não eram dados com regularidade pelas universidades brasileiras, mas na década de 1970 os cursos de pós-graduação no Brasil começaram a difundir-se ${ }^{10}$. Além disso, nessa década, começaram a aparecer os primeiros resultados do crescente apoio à atividades de pesquisa no Brasil. A origem dessa política foi a criação do Funtec (Programa de Desenvolvimento Técnológico), pelo BNDE, ainda na década de 1960. Mas esse tomou corpo e mostrou resultados com a atuação da FINEP, que, a partir de 1971, assumiu a responsabilidade de administrar o Fundo Nacional de Desenvolvimento Científico e Tecnológico ${ }^{11}$.

Fábio Erber recebeu, em 1970, uma bolsa do British Council, que permitiu que ele obtivesse um Mestrado em Economia do Desenvolvimento Econômico na Universidade de East Anglia, na Grã-Bretanha, em 1971. De volta ao Brasil, Fábio

\footnotetext{
${ }^{9}$ Dos três aspectos extraídos de Schumpeter, Fábio tratava este último com uma certa cautela. Como profundo conhecedor do temperamento dos empresários brasileiros, ele sempre foi um pouco cético à capacidade de resposta de vários deles a esse desafio competitivo. Ele considerava que muitos procuravam enfrentar a competição em vez de recorrer à inovação, através de outros artifícios, inclusive recorrendo, sempre que possível, de maneira espúria, ao Estado. Nesse sentido, ele via a ação do Estado, através de uma burocracia moderna e consciente, como uma forma de compensar essa relativa acomodação desses empresários brasileiros. Para ele, não havia uma oposição Estado x Mercado. Mas era a ação do Estado que criava as condições do mercado operar de forma eficaz. Ou, como chegava a comentar jocosamente, implantar o capitalismo apesar dos capitalistas.

${ }^{10}$ Em 1977, o número de programas universitários brasileiros já superava a casa dos seiscentos. Ver Schwartzman (1979, p. 297).

${ }^{11}$ Schwartzman (1979, p. 298-303) discute com detalhes o surgimento de uma política de ciência e tecnologia, como elemento de uma estratégia de desenvolvimento, no Brasil.
} 
participou da criação de um Grupo de Pesquisa na Finep, onde realizou estudos sobre as relações de desenvolvimento econômico e ciência e tecnologia, sobre a indústria de bens de capital e outros temas correlatos. Essa experiência levou-o a publicar dois artigos, ainda, na primeira metade da década. São artigos que expressavam as preocupações do debate brasileiro na tradição desenvolvimentista, mas que continham novidades que não estavam presentes no debate nacional, refletindo a experiência e os conhecimentos obtidos por ele em sua formação no exterior.

Em artigo publicado na PPE, em 1972, Fábio apresentou uma interessante contribuição à discussão sobre escolha de tecnologias e os problemas de oferta de trabalho e desenvolvimento regional ${ }^{12}$. $\mathrm{O}$ artigo levantava questões que eram relevantes para os principais debates desse momento histórico. Os primeiros anos da década foram marcados por dois debates sobre o desenvolvimento brasileiro:

i) a controvérsia sobre distribuição de renda;

ii) o debate sobre o modelo brasileiro.

O primeiro surgiu como resultado da análise dos dados do Censo de 1970. Com a publicação pelo IBGE dos dados dessa pesquisa decenal, verificou-se que se a economia brasileira cresceu aceleradamente depois de 1967, a década de 1960 marcou, também, um aumento significativo da desigualdade no país. Esse resultado era um ponto fraco, no argumento do governo militar de que a eficiência era o fundamento de sua legitimidade ${ }^{13}$. Esse debate tinha duas correntes antagônicas:

i) a que sustentava que a causa da deterioração da distribuição de renda no país era resultado das políticas públicas do governo militar;

ii) a que sustentava que a causa da distribuição de renda era os efeitos pelo aumento mais acelerado da demanda de mão-de-obra qualificada, com relação a mão de obra não qualificada ${ }^{14}$.

O segundo debate tem sua contribuição seminal com a publicação do livro de Celso Furtado: Análise do "Modelo Brasileiro"15. Esse economista argumentou que o Brasil era um caso paradigmático para a discussão da industrialização em condições de subdesenvolvimento. Furtado refutou a tese, generalizada no pós-guerra, de que a industrialização seria condição suficiente para a absorção do subdesenvolvimento ${ }^{16}$.

\footnotetext{
12 Ver Erber (1972).

${ }^{13}$ Para uma discussão detalhada da implicação desse debate para o momento histórico, ver Prado e Earp (2003). Para uma apresentação dos principais argumentos da controvérsia sobre a distribuição de renda ver Tolipan e Tinelli (1978).

${ }^{14}$ Ver Wells (1978).

${ }^{15}$ Ver Furtado (1972).

${ }^{16}$ Furtado (1972, p. 8).
} 
Segundo sua interpretação, o principal problema que defrontava o país era gerar fontes de emprego para sua numerosa e crescente população, grande parte da qual vivia em condições precárias, em setores urbanos marginalizados ou na agricultura de subsistência. Furtado via na importação de tecnologia um dos fatores que contribuíam para a não geração de empregos, em número e qualidade suficiente para absorver a oferta de trabalho pela população brasileira de baixa renda.

Erber (1972) partiu da constatação de que "a industrialização tal como vem sendo feita tem, sem dúvida, aumentado o produto, mas não produziu os efeitos que alguns esperavam na absorção de mão-de-obra". ${ }^{17}$ Mas, ainda, essa insuficiência era mais grave no Nordeste, onde depois de mais de uma década de investimentos maciços na indústria, permanece o problema de subutilização de mão de obra. O artigo contesta a tese de que a simples redução do custo da mão-de-obra, com referência ao custo do capital, levaria os empresários necessariamente a aumentar a utilização do fator trabalho. Nesse caso, a pergunta seria por que não foram escolhidas no Brasil tecnologias intensivas em mão-de-obra, que seria razoável, dada a oferta abundante de trabalho barato no Brasil. Mas, ao contrário, a industrialização brasileira caracterizava-se por investimentos intensivos em capital.

Erber levantou várias hipóteses para explicar essa aparente contradição. Em primeiro lugar, chamou atenção para o fato de que o investimento de longo prazo (no qual as escolhas tecnológicas estão embutidas) era financiado no Brasil com capital próprio, ou seja, com reinvestimento dos lucros, enquanto o capital de giro era financiado com crédito bancário. No caso, como o custo de oportunidade do capital próprio era baixo, os empresários preferiam aplicações poupadoras de mão-de-obra que levariam a economizar capital de giro, que era relativamente escasso e caro. Erber recorreu a artigos de Giovanni Arrighi e de Michael Todaro para mostrar que investimento em capital intensivo economizava a necessidade de empregados qualificados, que eram caros e escassos no Brasil ${ }^{18}$. Erber também acompanhou a interpretação de Furtado, de que os padrões de consumo no Brasil, que emulam os dos países mais desenvolvidos, implicam a importação de tecnologia estrangeira, que é desenhada para países onde o custo relativo da mão-de-obra é mais elevado. $\mathrm{O}$ artigo elabora, nesse contexto, a seguinte tese: a combinação de fatores de mercado e de distribuição de renda com a dependência de padrões de consumo elimina a possibilidade de escolhas de tecnologia para os bens de consumo no Brasil, em especial dos setores mais dinâmicos. Portanto,

\footnotetext{
${ }^{17}$ Erber (1972a, p. 105).

${ }^{18}$ Ver Arrighi (1969) e Todaro (1970). Os argumentos de um artigo escrito em italiano por Arrighi e os então atualíssimos debates sobre emprego urbano levantados por Todaro refletem a então recente formação europeia de Erber. Seu mestrado na Universidade de East Anglia contribuiu para trazer literatura que na época não era regularmente usada pelos autores brasileiros.
} 
a dependência dos padrões de consumo se consolida pela dependência da tecnologia de produção. As empresas estrangeiras operam com tecnologia trazida de suas matrizes, as brasileiras com tecnologia licenciada do exterior. Portanto, não há escolha de tecnologia possível em bens de consumo. Como em bens intermediários, também são reduzidas as alternativas tecnológicas, e todas essas alternativas são intensivas em capital - a industrialização no Brasil não poderia ser intensiva em mão-de-obra.

O artigo de Erber (1972) contribuiu, portanto, para o debate sobre distribuição de renda, já que mostrou que a industrialização brasileira era poupadora de mão-deobra em decorrência da natureza de seu modelo, como afirmava Celso Furtado, mas também em função da dinâmica da transferência de tecnologia, questão que, ainda, não era tratada em profundidade no Brasil.

O segundo artigo publicado na década de 1970 foi feito em coautoria com José Tavares de Araújo Jr e apresentava resultado da investigação que ambos realizavam no Grupo de Pesquisa da Finep ${ }^{19}$. Esse era um tema pioneiro, no qual tanto Erber como Araújo Jr viriam a fazer importantes contribuições ao longo de suas carreiras acadêmicas e profissionais. $\mathrm{O}$ artigo discutia as dimensões do setor de bens de capital:

i) a de criação de excedentes que são apropriados pelo resto do sistema econômico;

ii) a de ser veículo de incorporação e difusão do progresso tecnológico;

iii) a de evitar a limitação da taxa de crescimento da economia;

iv) a de permitir a autonomia política.

Erber e Araujo Jr (1973) trazem pela primeira vez à literatura econômica brasileira uma discussão sobre o progresso tecnológico através da análise das etapas de criação, incorporação e difusão, realizada através de atividades de pesquisas, desenvolvimento, engineering e administração, traduzindo-se economicamente na introdução de novos produtos ou na modificação dos já existentes ${ }^{20}$. O artigo defendeu a tese de que o setor de bens de capital tem papel estratégico para sustentar o dinamismo do sistema industrial. Nesse contexto, levanta algumas características desse setor, como (a) a de instabilidade, ou seja, ser um barômetro das oscilações cíclicas da economia, principalmente em decorrência das oscilações nas demandas por expansão dos investimentos; (b) a de heterogenidade, ou seja, a de envolver desde caldeirarias de fundo de quintal até os sofisticados complexos industriais; e finalmente (c) a de autonomia relativa em relação ao setor de bens de consumo. Ou seja, os setores de bens de capital e de bens intermediários combinados podem crescer com relativa independência do crescimento do setor de bens de consumo. Todas essas questões seriam posteriormente debatidas por extensa literatura sobre progresso técnico e desenvolvimento

\footnotetext{
${ }^{19}$ Ver Erber e Araújo Jr. (1973).

${ }^{20}$ Erber e Araujo Jr. (1973, p. 119).
} 
econômico, na qual as contribuições do grupo de pesquisa da Finep foram pioneiras. Além disso, esse debate vai ser o tema da tese de doutorado de Fábio Erber no IDS (Institute of Developing Studies), Universidade de Sussex, defendida em 1978 ${ }^{21}$.

Erber chega à Brighton no momento em que os estudos e ações do IDS e do SPRU, instituições que tinham sido criadas em 1969, abriam novos debates e promoviam grande impacto nas discussões sobre política do desenvolvimento. Alguns anos antes, em 1970, tinha sido publicado o "Manifesto do Grupo de Sussex", que foi o produto de uma encomenda das Nações Unidas a uma comissão de acadêmicos do IDS e do SPRU sobre o tema de ciência e tecnologia para o desenvolvimento. Esse grupo reunia um dos mais importantes teóricos de Teoria de Desenvolvimento no pós-guerra, Hans Singer; o economista Christopher Freeman, que foi um dos fundadores e Diretor do SPRU; Charles Cooper, economista britânico, que foi por vários anos joint-fellow do IDS e do SPRU e foi, posteriormente, um dos fundadores do centro do Instituto de Novas Tecnologias da Universidade das Nações Unidas (UNU-INTEC) em Maastrich, Holanda; o geofísico Geofrey Oldham; e, ainda, R.C. Desai, Oscar Gish e Stephen Hill. Até ao início da década de 1970, não havia uma preocupação com o desenvolvimento tecnológico dos países em desenvolvimento. Ao contrário, a visão generalizada era de que qualquer necessidade de tecnologia podia ser adquirida dos países industriais avançados e, portanto, investir em produção de Pesquisa e Desenvolvimento na periferia não era prioritário, podendo, inclusive, ser considerado um desperdício de recursos $^{22}$. O Manifesto põe na agenda, pela primeira vez, a necessidade de se promover desenvolvimento tecnológico e pesquisa nos países em desenvolvimento. $\mathrm{O}$ texto afirma que:

Há uma grade defasagem nos países em desenvolvimento entre a produção atual e a produção potencial através da aplicação da ciência e tecnologia. A análise desta situação é essencial para a proposta de uma política. (...). O problema surge da divisão internacional do trabalho em ciência e tecnologia e que dirige os esforços científicos para os problemas e objetivos que interessam os países mais avançados ${ }^{23}$.

Esse foi um momento singular para a produção acadêmica da literatura do desenvolvimento. Nesse período, o debate tradicional da chamada High Theory of Development entrava em decadência, o que foi observado com perspicácia por

\footnotetext{
${ }^{21}$ Ver Erber (1978).

${ }^{22}$ Para um testemunho de como era generalizada essa visão e de qual era o clima político em torno do Manisfesto de Sussex, ver o vídeo de conferência do Prof. Oldham, antigo diretor do SPRU, no SEPS Centre, do IDS e SPRU, em 2008. Esse material está disponível em www.blip.tv//file_types=flv;sort=date; date;id=1166090;s=file, acessado em maio de 2011.

${ }^{23}$ Singer et al., Sussex Manifesto (1970).
} 
Hirschman ${ }^{24}$. Alguns dos grandes teóricos dessa literatura continuaram suas atividades acadêmicas e sua militância pela promoção de políticas desenvolvimentistas em outras esferas: Prebish desde 1963 tinha ocupado uma posição de liderança na criação da UNCTAD e Hans Singer aceitou ocupar uma cátedra no recém-criado Institute of Developing Studies (IDS). Singer teve uma formação acadêmica singular: estudou com Schumpeter em Bonn e, como judeu alemão, viu-se na contingência de sair do país com a ascensão de Hitler em 1933. Schumpeter convenceu Keynes a recebê-lo em Cambridge como um dos seus primeiros estudantes de doutorado. A reunião de Singer e Freeman, assim como as de vários outros intelectuais, fizeram de Sussex um ambiente instigante e singular naquele momento. A introdução do tema de Pesquisa e Tecnologia no debate sobre desenvolvimento iria abrir toda uma nova agenda de pesquisa. O debate sobre o Tecnologia e Crescimento passou a ser importante não apenas para os chamados economistas neoschumpeterianos, atores como Romer e outros economistas de crescimento endógeno ${ }^{25}$.

Erber, que conviveu com esse debate em Sussex, trouxe para o Brasil a sua formação e experiência desse momento histórico e, nas décadas seguintes, tornou-se um dos mais importantes autores do tema de Política Tecnológica e Desenvolvimento no Brasil.

\section{CRISE dO DESENVOLVIMENTISMO E O FRACASSO DA POLÍtICA TECNOLÓGICA}

A década de 1980 foi marcada pelo fim do governo militar e pela crise do que, posteriormente, seria chamado por Erber de Convenção do Desenvolvimento ${ }^{26}$. Foi um período de intensa produção intelectual e, na Nova República, Erber ocupou, pela primeira vez, uma posição política na estrutura governamental: foi Secretário-Executivo adjunto, no Ministério de Ciência e Tecnologia, quando o Secretário Executivo era Luciano Coutinho, e o Ministro era Renato Archer. Nessa década, foi extinto o Grupo de Pesquisa da FINEP e Erber assumiu a posição de Professor titular de História e Desenvolvimento do IEI-UFRJ.

Desde o retorno do doutorado, Erber publicou vários artigos e capítulos de livros resenhando e discutindo a literatura de Política Científica e Tecnológica ${ }^{27}$. Esse tema tinha à época várias leituras, mas no campo da política tecnológica o tema mais candente era a política brasileira de informática e do desenvolvimento da indústria de computadores. A constatação de Erber era que embora durante o regime militar houvesse uma política de engajamento de instituições federais em atividades de pesquisa sobre o desenvolvimento científico e tecnológico, a capacidade tecnológica do parque industrial brasileiro concentrava-se na

\footnotetext{
${ }^{24}$ Ver Hirschman (1984). Sobre o debate da decadência da High Theory of Economic Development, ver Krugman (1993) e Prado (1993).

${ }^{25}$ Ver Romer (1990) e ver, ainda, Erber (2010).

${ }^{26}$ Ver Erber (2010, 2011).

${ }^{27}$ Ver Erber $(1979,1980)$.
} 
fabricação e na engenharia de detalhe ${ }^{28}$. Para ele, novos produtos e processos tendiam a apoiar-se na importação de tecnologia. Essa importação levava a um aprendizado, mas não alcançava atividades tecnológicas mais complexas, necessárias para que as inovações não fossem incrementais. Para ele a exceção eram algumas empresas estatais à "mercê de sua ambiguidade estrutural, ao serem, ao mesmo tempo, empresas e Estado"ng.

Erber participou, também, na década de 1980, dos debates sobre política de informática no Brasil e sobre Propriedade Intelectual e competição entre empresas. O tema de política de informática e indústria de computadores foi um dos assuntos mais candentes na área de ciência e tecnologia na primeira metade da década de 1980. A disputa em torno da criação da indústria de informática no Brasil, que deveria incluir a produção de computadores, equipamentos de telecomunicação, componentes e software, envolveu acadêmicos na área tecnológica, tecnocratas, economistas, burocratas, setores das forças armadas, setores do aparato de segurança do governo militar e, ainda, industriais e executivos brasileiros e estrangeiros.

A tentativa de implementar esse projeto, que perdurou desde os governos militares até a Nova República, foi uma experiência ousada, que foi chamada por Emanuel Adler de "Ideological Guerrillas for Technological Autonomy"30. Erber não foi um protagonistas dessa militância. Esse papel deve ser atribuído a engenheiros como Ivan da Costa Marques, ao comandante José Guaranys, mas também a economistas, como Paulo Bastos Tigres; que, tal como Erber, era professor do IEI-UFRJ e doutor por Sussex. Erber foi, no entanto, um analista cuidadoso dessa disputa e um artigo, publicado em livro de Bastos e Cooper, em 1995, é um dos mais interessantes avaliações realizadas dessa experiência ${ }^{31}$.

Um trabalho importante de Erber, da década de 1980, versa sobre propriedade industrial e competição entre empresas ${ }^{32}$. A visão dos países industriais avançados para Propriedade Intelectual é que elas são iguais a qualquer outra forma de propriedade, portanto, elas não são, isoladamente, fonte de poder de mercado, sob o ponto de vista da legislação antitruste ${ }^{33}$. As autoridades antitrustes norte-americanas chegam inclusive a deixar claro nos Guidelines de Propriedade Intelectual que "The Agencies will not require the owner of intelectual Property to create competition in

\footnotetext{
${ }^{28}$ Ver Erber (1979) e ver sua releitura desse período em Erber (2010).

${ }^{29} \operatorname{Erber}$ (2010, p. 17).

${ }^{30}$ Adler (1986).

${ }^{31}$ Ver Erber (1995). Ver, também, o artigo de Erber (1989), publicado como Texto de Discussão, do IE-UNICAMP.

${ }^{32}$ Ver Erber (1982).

${ }^{33}$ Buccirossi (2008, p. 521).
} 
its own technology" ${ }^{34}$. Erber discute as questões que envolvem a propriedade industrial como instrumento de competição entre empresas e como objeto de política pública. Esse é um artigo que trata dessa questão polêmica, sob a perspectiva de um país em desenvolvimento, mas de uma maneira objetiva, avaliando os ganhos e cautelas necessárias para uma política nacional de patentes ${ }^{35}$.

Erber não era um macroeconomista, mas, como um economista do desenvolvimento, acompanhava as políticas públicas, discutindo, como professor de economia brasileira, as políticas de combate à inflação que dominaram a imprensa no Brasil ao final da década de 1980. Em sua interpretação, o fracasso do cruzado foi o começo do fim do consenso em torno de uma política desenvolvimentista no Brasil. Essa ideia, que começou a se formar ao final da década de 1980, seria elaborada durante a década de 1990, resultando nos seus trabalhos sobre convenção de desenvolvimento ${ }^{36}$.

Ao final da década de 1980, a frustração da população brasileira com a incapacidade de o primeiro governo civil, depois do regime autoritário, garantir condições econômicas minimamente estáveis e previsíveis, criou condições para mudanças profundas no quadro eleitoral. Nesse contexto, eleitores movidos por protesto e medo levaram ao poder um aventureiro, produto de uma nova direita, o ex-governador de Alagoas, Fernando Collor de Melo. Erber analisou a política industrial do Governo Collor em livro escrito com Vermulm, em 1993, onde mostra que a ideia do governo era fazer uma política em forma de pinça, por um lado criando mecanismos de estímulo à competitividade e de outro forçando a concorrência através de uma abertura comercial unilateral ${ }^{37}$. Ao fim do governo Collor, nada mais resta da agenda desenvolvimentista. Os ventos do liberalismo sopram fortes no Brasil. Depois do interregno do governo Itamar e do sucesso do Plano Real, o novo governo FHC marca a ascensão de uma nova convenção na economia brasileira. A partir da segunda metade da década de 1990, Erber iniciará uma discussão que se aproxima da sociologia econômica para entender a natureza das forças políticas que determinam as estratégias de desenvolvimento no Brasil.

\footnotetext{
${ }^{34}$ Ver IP Guidelines $\$ 3$.

${ }^{35}$ Para um survey dos debates contemporâneos sobre o tema, ver Hall (2007).

${ }^{36}$ Em especial, Erber $(2011,2010)$.

${ }^{37}$ Erber (1993). Erber retornou ao tema em trabalho que escrevemos juntos sobre o governo Collor para um livro de História Econômica do Brasil que nunca chegou a ser publicado. Este trabalho permanece inédito.
} 


\section{DE FHC À LULA: CONVENÇÕES DE DESENVOLVIMENTO NO BRASIL CONTEMPORÂNEO}

A vitória norte-americana na Guerra Fria e a excepcional taxa de crescimento da economia norte-americana nesse período marcou o imaginário da década ${ }^{38}$. Stiglitz definiu o sentimento do momento histórico da seguinte forma:

Não era apenas o capitalismo que havia triunfado sobre o comunismo; a versão americana do capitalismo, baseada em uma imagem de individualismo rude, parecia ter triunfado sobre outras versões mais brandas, menos assumidas. Em encontros internacionais, tais como o G-7, (...) vangloriávamo-nos do nosso sucesso e recomendávamos aos líderes econômicos de outros países, às vezes invejosos, que bastaria nos imitar para que também desfrutassem de prosperidade ${ }^{39}$.

Nesse clima, o sucesso do Plano Real criou condições políticas para a implementação de uma agenda de reformas liberais. As políticas desenvolvimentistas tinham ficado desmoralizadas com o fracasso do Plano Cruzado. A ideia de uma redução do papel do Estado na economia era sedutora para uma sociedade cansada de intervenções radicais que culminaram no congelamento de depósitos privados pelo Plano Collor. Nessas condições de incerteza, não era facilmente percebido pela massa de eleitores que políticas atendiam seus interesses individuais. Ao contrário, esses interesses eram formulados e difundidos pela construção de um conjunto de políticas, que representaria o pensamento dominante de uma imensa coalizão que englobava economistas ortodoxos, a grande imprensa, as organizações empresariais e grande parte do Congresso Nacional. A base desse Consenso, proposto por uma nova e ousada militância liberal, seria uma agenda de reformas liberais ${ }^{40}$.

Erber percebeu esse período, ao mesmo tempo fascinado e preocupado com o momento histórico. Com uma vasta cultura literária e com sua experiência na formulação de políticas econômicas, percebia que o discurso do governo FHC era absorvido pela população por razões que transcendiam o argumento econômico. Erber mostrou que a ideia de um Mito da Travessia, presente nas mitologias e nas religiões, era inteiramente consistente com o argumento das reformas liberais ${ }^{41}$. Tratava-se de enfrentar uma provação que, uma vez vencida, levaria os crentes à vitória final: à terra prometida.

\footnotetext{
${ }^{38}$ Para dados sobre o Neoliberalismo e o crescimento dos EUA no período ver Kootz (2003).

${ }^{39}$ Ver Stiglitz (2003, p. 33-34).

${ }^{40}$ Há uma imensa literatura sobre esse tema. Como referência desses debates, ver Schneider, 2004, para uma discussão das alianças políticas das reformas. Ver também, para uma discussão econômica dessa agenda, Bates e Krueger (1993) e Haggard e Kaufman (1992). Para uma resenha dessa literatura, ver Geddes (1995).

${ }^{41}$ Ver Erber $(2002,1996)$.
} 
Se a economia não crescia, se os problemas da Balança de Pagamento não eram resolvidos, se o desemprego era elevado, eram os custos da transição. O liberalismo desses anos não seria apenas uma nova forma de conservadorismo: era uma forma nova de ativismo revolucionário. Não se tratava de conservar, mas de mudar a sociedade brasileira, construindo uma base política para uma nova estratégia de desenvolvimento.

O tratamento teórico de Erber a essas questões, que começaram a ser formuladas na década de 1990, foram sistematizadas em um conjunto de artigos, escritos neste século, no seu estudo sobre Convenções em Economia. Mas já estava presente em meados da década de 1990. Para ele, o debate sobre política econômica não podia ser reduzido a uma questão exclusivamente técnica. Em suas palavras: “... parte-se do princípio epistemológico de que a economia é ontologicamente política." Portanto, sua abordagem movia-se na "contramão da visão de que os conflitos [de política econômica] são exclusivamente técnicos"42.

A eleição de Lula em 2003 levaria Fábio Erber à sua última atuação em um cargo de governo. Durante a gestão de Carlos Lessa como Presidente do BNDES, Erber ocupou pela segunda vez uma diretoria no Banco. Esse foi um período conturbado, pois Erber tinha divergências com a maneira em que Lessa dirigia o Banco. Porém, embora não concordasse com a forma das críticas de Lessa à política monetária do governo, Erber concordava com sua natureza e sentia-se desconfortável em ter que negociar com economistas que durante toda a vida foram duros adversários das políticas defendidas pelos economistas simpáticos ao PT, e que dominavam o Ministério da Fazenda em um governo do PT. Isso não impediu que Erber exercesse com eficácia suas atividades, tendo um papel essencial na formulação do PITCE- Política Industrial, Tecnológica e de Comércio Exterior.

As bases da política industrial do primeiro governo Lula foram divulgadas em junho de 2003, através do texto Roteiro para Agenda de Desenvolvimento. Em novembro de 2003, foi divulgado o documento Diretrizes de Política Industrial, Tecnológica e de Comércio Exterior ${ }^{43}$. Esse foi um documento inovador, que se distinguia dos modelos de política industrial desenvolvimentistas e, também, dos modelos de política industrial horizontais, mais afeitos às políticas market friendly da década de 1990. Com efeito, essa política selecionava setores a serem incentivados entre os que eram os instrumentos de mudança e de criação de novas competências. O objetivo era articular as dimensões vertical (setores escolhidos para terem apoio, incentivo, fomento de forma diferenciada) e horizontal (os demais setores, que receberiam os efeitos dinâmicos pro-

\footnotetext{
${ }^{42}$ Ver Erber (2011, p. 32).

${ }^{43} \mathrm{O}$ documento foi assinado pela Casa Civil, Pelo MDIC, pelo Ministério da Fazenda, pelo Ministério de Planejamento, pelo Ministério de Ciência e Tecnologia, pelo BNDES, pelo IPEA, pela FINEP.
} 
porcionados pelos setores escolhidos $)^{44}$. A primeira política industrial do governo Lula não foi, no entanto, implementada. Havia uma notória falta de interesse do Ministério da Fazenda, sob a gestão de Palocci, de levar adiante uma política industrial ativa. Somente após a saída desse ministro, e a ascensão de Mantega, com uma nova equipe, mais sintonizada com os economistas industriais, para que fosse possível implementar uma política industrial ativa no país ${ }^{45}$. Nessa ocasião, no entanto, Erber já tinha saído do governo e retornado a suas atividades acadêmicas.

Com seu retorno ao IE-UFRJ, Erber refletiu sobre sua experiência de governo e sobre os problemas de mobilização para viabilizar uma política de desenvolvimento. Em um conjunto de artigos, formulou sua tese sobre Convenções de Desenvolvimento no Brasil Contemporâneo ${ }^{46}$. Erber define Convenção como um dispositivo cognitivo compartilhado por uma população $\mathrm{P}$, que segue um comportamento $\mathrm{C}$, adotado por todos os membros de $\mathrm{P}$, na suposição de que todos os membros de $\mathrm{P}$ o compartilharão ${ }^{47}$. Uma convenção surgiria da interação entre atores sociais, mas é externa a esses atores e não pode ser reduzida à sua cognição individual - ou seja, é um fenômeno emergente, em que o todo não é redutível às partes. Instituições provêm à sociedade meios para lidar com os problemas de incerteza e coordenação, ou seja, estabelecendo as regras do jogo.

Para Erber, nas condições de incerteza do primeiro governo Lula, a necessidade de construir uma política mais inclusiva do ponto de vista social, mas compatível com a redução dos riscos políticos, advindos de um temor de que esse governo não teria compromissos com a estabilidade monetária, levou à construção de duas convenções distintas. A primeira seria uma Convenção Institucionalista, apresentada pelo Ministério da Fazenda e pelo Banco Central, que sustentava uma visão de sociedade competitiva e meritocrática, cuja eficiência é garantida pelo funcionamento do mercado. O cerne analítico dessa convenção era neoclássico, enriquecido do aporte da Nova Economia Institucional ${ }^{48}$. Convivendo com a outra, mas subordinada a ela, foi formulada uma Convenção neo-desenvolvimentista. Essa abordagem tem uma

\footnotetext{
${ }^{44}$ Ver para discussão das questões recentes de Política Industrial no Brasil, inclusive uma avaliação do PITCE, Suzigan e Furtado (2010).

${ }^{45}$ Além de não ser implementada, a PITCE muitas vezes não é lembrada pelos gestores das principais institutições da área. Ver Suzigan e Furtado (2010, p. 20). Uma visão contrária a esta interpretação me foi manifestada por Dulce Monteiro Filha, economista do BNDES, que foi assessora de Erber no Banco. Dulce afirma que o BNDES implementou vários planos dessa política e que os principais pontos do PITCE , que Erber julgava importantes, foram mantidos na política industrial posteriormente implementada no governo Lula.

${ }^{46}$ Ver Erber $(2011,2010,2009,2008)$.

${ }^{47}$ Ver Erber (2010, p. 3).

${ }^{48}$ Erber refere-se a autores como North (1990).
} 
visão de sociedade essencialmente cooperativa, expressa através do conceito de pacto social e da prioridade à inclusão social. Erber apontava que essas convenções têm diferentes visões e núcleos duros distintos e atendem a diferentes interesses. Tais diferenças se traduzem em diferentes prioridades de modificação estrutural postuladas pelas duas convenções em agendas políticas distintas. Nesse contexto teórico, Erber discutiu a economia política do governo Lula, apontando seus avanços, mas expondo suas contradições e seus impasses. Essa abordagem apontava para toda uma linha de pesquisa sobre a dinâmica dessas Convenções, que não chegou a ser desenvolvida pelo autor, devido a sua morte prematura em fevereiro de 2011.

\section{CONCLUSÃO}

Fábio Erber foi um representante da primeira geração de intelectuais formados no exterior com o apoio do governo brasileiro. Sua produção acadêmica foi resenhada neste ensaio, em que se mostrou como ela influenciou e refletiu as principais questões de Política Industrial e Tecnológica do país, ao longo das quatro décadas em que foi escrita. Erber foi um economista do desenvolvimento que influenciou a vida brasileira através de sua produção acadêmica, de suas funções públicas e de sua atividade de professor. Embora não fosse marxista, não tenho dúvida de que Erber concordaria com a XI Tese sobre Feurerbach, proposta por Marx: "Os filósofos [ou talvez os economistas] não fizeram mais do que interpretar o mundo, porém o que importa é transformá-lo" ${ }^{\prime 4}$.

\section{REFERÊNCIAS}

ADLER, E. 'Ideological 'Guerrillas' and the Quest for Technological Autonomy: Brasil's domestic Computer Industry”, International Organization, v. 40, n. 3, 1986, p. 673-705.

ARRIGHI, G. Sviluppo Economico e Sovrastrutture in Africa, Torino: Einaudi, 1968.

BATES, R.;KRUEGER, A. (Org). Political and Economic Interactions in Economic Policy Reform, Cambridge, Mass: Basil Blackweel, 1993.

BUCCIROSSI, P. Handbook of Antitrust Economics, Cambridge Mass.: MIT Press, 2008.

ERBER, F. S. "Escolha de Tecnologias, Preços dos Fatores de Produção e Dependência - Uma contribuição ao Debate", Pesquisa e Planejamento Econômico, Rio de Janeiro: v. 2, n. 1, 1972.

"A propriedade Industrial como Instrumento de Competição entre empresas e objeto de política estatal”, Política e Planejamento Econômico, dez, 1982, p. 915-952.

\footnotetext{
${ }^{49} \operatorname{Marx}(1975$, p. 406).
} 
“Microeletrônica, Reforma ou Revolução?” Revista Brasileira de Tecnologia, v. 15, n. 1,1984

"The Development of the Electronics complex and government Policies in Brasil", World Development, v. 13, n. 1, 1985

"The Political Economy of Technological Development: The Case of the Brasilian Informatics Politics" em BASTOS, M. I.; COOPER, C. Politics of Technology in Latin America, New York: UNU/INTEC Studies in New Technologies and Development, Routledge, 1995.

. "O Mito da Travessia e a Retórica do Governo", Boletim de Conjuntura, v. 16, n. 2, IE/UFRJ, 1996.

Política Industrial Nacional e Política de Informática Nacional, Texto para Discussão, IE-Unicamp, 1996.

"Brazilian Development in the nineties - myth, cycles and structures", Nova Economia, v. 12, n. 1, 2002.

"The Evolution of Development Conventions", Rio de Janeiro: XXII International Schumpeter Society Conference, 2008.

. "Convenções de Desenvolvimento no Brasil Contemporâneo", Insight Inteligência, ano XI, n. 44, 2009.

Convenções de Desenvolvimento no Brasil Contemporâneo: um Ensaio de Economia Política, Textos Para Discussão Cepal-Ipea, 2010a.

Inovação Tecnológica na Indústria Brasileira no Passado Recente: Uma Resenha da Literatura Econômica - Textos para Discussão Cepal-Ipea, $2010 \mathrm{~b}$.

"As Convenções de Desenvolvimento no Governo Lula", Revista de Economia Política", v. 31, n. 1, jan.-mar. de 2011.

ERBER, F.S.;ARAÚJO, J.T. de - "Notas sobre a Industria de Bens de Capital: Tecnologia e Setor Público, Pesquisa e Planejamento Econômico, v. 3, n. 1, 1973.

ERBER, F.S. VERMULM, R. Ajuste Estrutural e Estratégias Empresariais, Rio de janeiro: IPEA, v. 1, 1993.

FAJNZYLBER, F. "Industrialização na América Latina: da "caixa-preta" ao "conjunto-vazio", em BIELSCHOVSKY, R (org), Cinquenta Anos de Pensamento na Cepal, Rio de Janeiro: Editora Record, 2000.

FURTADO, C. Análise do "Modelo Brasileiro", Rio de Janeiro: Civilização Brasileira, 1972.

FURTADO, C. Formação Econômica do Brasil, Rio de Janeiro: Editora Fundo de Cultura, 1959.

GEDDES, B. “The Politics of Economic Liberalization”, Latin American Research Review, v. 30, n. 2, p. 195, abr. de 1995. 
HAGGARD, S.; KAUfMAN, R. The Politics of Economic Adjustment, Princeton: Princeton University Press, 1992.

HALL, B.H. "Patents and Patent Policy", Oxford Review of Economic Policy, v. 23, n. 4, p. 568-587, 2007.

HIRSCHMAN, A. O."Grandeza e Decadência da Teoria do Desenvolvimento", em A Economia Como Ciência Moral e Política, São Paulo: Brasiliense, 1984.

HOBSBAWM, E. On History, London: Weidenfeld \& Nicolson, 1997

JOHNSON, H. Comparative Cost and Commercial Policy Theory, Stockholm: Wicksell Lectures, 1968.

KOTZ, D. "Neoliberalism and the US Economic Expansion of the 1990's, Montly Review, n. 54, p.15-35, 2003.

KRUGMAN, P. "Toward a Counter-Counterrevolution in Developing Theory”, Procedings of the World Bank Annual Conference of Development Economics, Washington, D.C.: World Bank, 1992.

LINDER, S. An Essay on Trade and Transformation, New York: Wiley, 1961.

MARSHALL, T.H. Cidadania, Classe Social e Status, Rio de Janeiro: Zahar Editores, 1967.

MARX, K. “Tesis sobre Feurerbach”, em Marx, K. \& Engels, Obras Escogidas, Tomo II, Madrid: Editorial Ayso, 1975.

NORTH, D. Institutions, Institutional Change and Economic Performance, Cambridge: Cambridge University Press, 1990.

POSNER, M. International Trade and Technical Change, Oxford Economic Papers, v. 13, out., p. 323-341.

PRADO, L.C.D. “Teoria do Desenvolvimento Econômico e Padrões Históricos de Industrialização: Uma Perspectiva Neo-Desenvolvimentista”, ENCONTRO NACIONAL DE ECONOMIA, XXI, 1993, Belo Horizonte. Anais, Belo HorizonteMG: ANPEC, p. 439-459, 1-3/dez., 1993.

PRADO, L.C.D.; EARP, F.S.“O “Milagre Brasileiro”: Crescimento Acelerado, Integração Internacional e Concentração de Renda (1967-1973)” em Ferreira e Delgado, O Brasil Republicano: O tempo da ditadura, Rio de Janeiro: Civilização Brasileira, 2003.

SCHUMPETER, J. "Development", com introdução de Markus C.Becker, Hans Ulrich Eblinger, Ulrich Hedtke and Thordjorn Knudsen, Journal of Economic Literature, V.XLII, March, p.108-120, 2005.

SCHUMPETER, J. A Teoria do Desenvolvimento Econômico, São Paulo: Nova Cultural, 1988.

SCHWARTZMAN, S. Formação da Comunidade Científica no Brasil, Rio de Janeiro: FINEP, 1979. 
SINGER, H.; COOPER, C.; DESAI, R.C.; FREEMAN, C.; GISH, O.; HILL, S.; OLDHAM, G. The Sussex Manifesto: Science and Tecnology to Developing Countries during the Second Decade, Brighton: IDS Reprints 101, Institute of Development Studies at the University of Sussex, 1970.

STIGLITZ, J. E. Os Exuberantes anos 90: Uma nova interpretação da década mais própera de nossa história, Rio de Janeiro: Companhia das Letras, 2003.

SUZIGAN, W.; FURTADO, J. “Instituições e Políticas Industriais e Tecnológicas, Reflexões a Partir da Experiência Brasileira”, Estudos Econômicos, São Paulo: v. 40, n. 1, p. 7-41, jan.-mar., 2010.

TODARO, M. Urban Employment Problems in Less Developmed Countries: An Anysis of Demand and Supply, New Haven: Yale University, 1968.

TOLIPAN, R.; TINELLI, A.C.A Controvérsia sobre a Distribuição de Renda e Desenvolvimento, Rio de Janeiro: Zahar, 1978.

United States Department of Justice (USDJ) \& Federal Trade Commission - Antitrust Guidelines for the Licensing of Intellectual Propriety, 6 de abr., 1995.

WELLS, J. "Distribuição de Rendimentos, Crescimento e a Estrutura de Demanda no Brasil na década de 1960" em TOLIPAN, R.; TINELLI, A.C. (org.). A Controvérsia sobre a Distribuição de Renda e Desenvolvimento, Rio de Janeiro: Zahar, 1978. 